\title{
Promoting less-than-full-time (LTFT) training in your local trust: a workshop in conjunction with your champion of flexible training
}

\author{
Authors: Shairoz Samji ${ }^{A, B}$ and Helen Cattermole ${ }^{B}$
}

\section{Introduction}

Recent Royal College of Physicians data have shown a continued increase in the proportion of trainees working less than full time (LTFT) to $15 \%{ }^{1}$. Despite this increase, the latest GMC survey data have shown that only about $15 \%$ of LTFT medical trainees feel very supported in their decision to train flexibly, versus $33 \%$ of GP trainees. ${ }^{2}$ What can be done at the grass roots level to improve LTFT training for all and to support trainees positively in their decision to work LTFT?

As part of the new junior doctor contract in 2016, flexible champions were put forward as a local point of contact for LTFT trainees. ${ }^{3}$ Guidelines have been provided by NHS Employers and the British Medical Association (BMA) for how this role should be implemented, ${ }^{3}$ but within my role as the LTFT representative to the Yorkshire regional Junior Doctor Committee (YrJDC), I have often found that most trainees tell me that they do not know who their champion is. There is no openly available list of flexible champions for trainees to access and, as such, knowledge of your flexible champion is often passed on through word of mouth.

\section{Methods}

The flexible champion and the trust have been looking to find new ways of improving LTFT training in Hull and East Yorkshire NHS Trust (HEY). As the LTFT rep to the YrJDC, I offered to run a workshop about topics which are particular to LTFT training. We know that there are 54 trainees working LTFT in this teaching hospital. A workshop was run in February 2019 in the Medical Education Centre inviting all trainees (full time and LTFT) to learn more about LTFT pay and rostering. This included a presentation from the HEY medical staffing team, which resulted in the creation of a new post within their department to support LTFT trainees and their specific rota needs. In order to widen access to the information, the workshop was filmed and will be available for all trainees on the trust intranet. Feedback forms were completed in order to judge the trainees' perception of the workshop.

Authors: ${ }^{A}$ Yorkshire Regional Junior Doctor Committee; ${ }^{B}$ Hull and East Yorkshire NHS Trust, Yorkshire, UK
Table 1. Specialty trainees attending the workshop

$\begin{array}{ll}\text { Specialty } & \text { Number of trainees (\%) } \\ \text { Academic } & 1(7.1) \\ \text { Anaesthetics } & 1(7.1) \\ \text { Emergency medicine } & 2(14.3) \\ \text { General practice } & 3(21.4) \\ \text { Oncology } & 1(7.1) \\ \text { Paediatrics } & 2(14.3) \\ \text { Radiology } & 3(21.4) \\ \text { Unnamed } & 1(7.1) \\ \text { Total } & 14\end{array}$

\section{Results and discussion}

Feedback forms were completed by over $75 \%$ of the 20 attendees. Participants included senior management $(n=2)$ and trainees $(n=17)$, as well as one rota coordinator. The workshop was attended by trainees from many specialties, of whom 14 completed the feedback form (Table 1). Three foundation trainees and three general practitioner trainees attended. The majority (57\%) were specialty trainees.

When asked whether the trust is supportive of LTFT training, $27 \%$ of participants felt that the trust scored the highest score on a Likert scale. Eighty per cent of those who completed the feedback form rated the workshop excellent to good.

\section{Conclusion}

Trainees found that the workshop met their needs. The concept of the workshop is being promoted nationally through a blog on the BMA website ${ }^{4}$ and steps are being taken on a national level to improve information about flexible champions to all trainees by the national lead in LTFT training. A further workshop will be held in HEY in May 2019. Topics will include maternity, paternity and shared parental leave. 


\section{References}

1 Royal College of Physicians. Census of consultant physicians and higher specialty trainees 2017-18. London: RCP, 2018. www. rcplondon.ac.uk/census [Accessed 22 March 2019].

2 General Medical Council. Training environments 2018: Key findings from the national trainee surveys. GMC/NTS2018KF/1118. Manchester: GMC, 2018. www.gmc-uk.org/-/media/documents/ training-environments-2018_pdf-76667101.pdf [Accessed 22 March 2019].
3 NHS Employers. Good practice guidance for flexible training champions. London: NHS Employers, 2017. www.nhsemployers.org/ your-workforce/pay-and-reward/medical-staff/doctors-and-dentistsin-training/terms-and-conditions-contracts/champions-of-flexibletraining-guidance [Accessed 22 March 2019].

4 Samji SS. Promoting LTFT training in your trust: The role of flexible champions. London: BMA, 2019. www.bma.org.uk/connectingdoctors/my_working_life/b/weblog/posts/promoting-ltft-training-inyour-trust-the-role-of-flexible-champions [Accessed 22 March 2019]. 